\title{
CONTEXTO PALEOAMBIENTAL PARA LA OCUPACIÓN ARQUEOLÓGICA EN CORRAL GRANDE (ANTOFAGASTA DE LA SIERRA, CATAMARCA, ARGENTINA)
}

\author{
PALEOENVIRONMENTAL CONTEXT OF THE ARCHEOLOGICAL OCCUPATION \\ IN CORRAL GRANDE (ANTOFAGASTA DE LA SIERRA, CATAMARCA, \\ ARGENTINA)
}

Pablo Tchilinguirian ${ }^{1}$, Lorena Grana ${ }^{2}$ y Daniel Olivera ${ }^{3}$

\begin{abstract}
El objetivo del trabajo es reconstruir la paleohidrología de la localidad Corral Grande (Departamento de Antofagasta de la Sierra, Catamarca, Argentina), relacionando la formación y crecimiento de la vega con la variación del balance hídrico. Con ello se pretende brindar un contexto ambiental al modelo de ocupación humana en esta localidad. Para ello, se analizó la geomorfología, la sedimentología, los microfósiles (diatomeas) y se efectuaron dataciones radiocarbónicas en el paraje de Corral Grande, situado en la confluencia de los ríos Mojones y Los Nacimientos. Los resultados indican que entre ca. 2000 a 1800 años AP los ríos fueron permanentes y se desarrolló una llanura de inundación con suelos orgánicos e hidromórficos y con una capa freática aflorante. Las ocupaciones de los sitios con cronología del Formativo fueron contemporáneas y se situaron cerca de este paleoambiente. Luego de los 1800 y hasta los 300 años AP la paleovega se erosionó y fue cubierta por sedimentos gruesos asociados a eventos aluviales de alta energía o de remoción en masa (flujo de detritos). Este paleoambiente coincidió en algún momento con la ocupación del TardíoInka. Posteriormente, entre ca. 300 y 240 años AP, el río Mojones volvió a desarrollar una vega con suelos orgánicos, pero de menor extensión que la Formativa. Finalmente, desde los 240 años AP hasta la actualidad se produce un proceso de degradación y retracción de la vega orgánica aguas arriba de los sitios arqueológicos.
\end{abstract}

Palabras claves: geoarqueología, Puna, paleohidrología.

This paper aims to reconstruct the palaeohydrological changes in Corral Grande (Antofagasta de la Sierra Department, Catamarca Province, Argentina), relating the formation and growth of a paleowetland with the hydrological balance in the high catchment area. This study provides, therefore, an environmental context for human occupation in this region. To this end, geomorphology, sedimentology, and microfossil (diatoms) analyses as well as radiocarbon datings were carried out in the confluence of Mojones and Los Nacimientos streams. Results indicate that between ca. 2000-1800 BP the rivers were permanent and the floodplains, where the Formative occupation occurred, had organic soils and a shallow water table. Between ca. 1800 and $300 \mathrm{BP}$ the paleowetlands were eroded and/or were covered by sediments associated with debris flows. This environment was sometimes contemporary with the occupation of the Late Inca Period, and the settlements were located in geoforms away from the paleowetland. Later, between ca. 300 and 240 BP, the Mojones river developed new, but less extensive, paleowetlands, and were shortly after deteriorated and retracted upstream.

Key words: Geoarcheology, Puna, paleohydrology.

Lasinvestigaciones arqueológicas y paleoambientales han demostrado que la mayoría de las ocupaciones humanas en Antofagasta de la Sierra (Puna sur de Argentina) se han establecido en relación estrecha con el agua, ya que su presencia es necesaria para el consumo (humano y animal), el riego, el forraje y la caza. Es por ello que se registran diversas ocupaciones permanentes con distintos modos de organización social que se ubican asociados a ríos o lagunas con agua permanente/ semipermanente. Así ocurre, por ejemplo, con los sitios Formativos como Casa Chávez Montículos (Olivera 1992) que se halla a $100 \mathrm{~m}$ de la vega del río Punilla;

\footnotetext{
${ }^{1}$ Universidad de Buenos Aires, Facultad de Ciencias Exactas y Naturales, Depto. de Ciencias Geológicas y CONICETInstituto Nacional de Antropología y Pensamiento Americano. Buenos Aires, Argentina. pabloguirian@gmail.com

${ }^{2}$ Facultad de Ciencias Agrarias, Universidad Nacional de Jujuy, Argentina. lorenaggrana@yahoo.com.ar

${ }^{3}$ Universidad de Buenos Aires. Facultad de Filosofía y Letras y CONICET-Instituto Nacional de Antropología y Pensamiento Latinoamericano (INAPL). Buenos Aires, Argentina. deolivera@gmail.com
}

Recibido: octubre 2017. Aceptado: junio 2018.

http://dx.doi.org/10.4067/S0717-73562018005001502. Publicado en línea: 7-agosto-2018. 
Las Escondidas (Escola et al. 2013) situado a $200 \mathrm{~m}$ del antiguo paleocauce del río Miriguaca entre otros. Y los sitios del período del Tardío-Inka como Volcán Alumbrera (Olivera et al. 2015) y Alumbrera (Olivera y Vigliani 2000-2002) que se sitúan a $100 \mathrm{~m}$ de la laguna Antofagasta.

En la cuenca inferior del río Mojones, ubicado en el sector oeste de la cuenca Punilla, se han registrado cinco sitios arqueológicos conocidos como Corral Grande (CG1 a CG5) (Figura 1). El material en superficie y la arquitectura registrada en estos sitios indican la existencia de ocupaciones asignables a diversos momentos, que van desde el Formativo (30001500 años AP), Tardío-Inka (1100 AP - ca. 450 años AP) y hasta momentos históricos; incluso se hallaron puntas de proyectil en superficie que se correlacionan con momentos de cazadores-recolectores arcaicos (6000-3000 años AP) (Olivera et al. 2008; 2015). Estos sitios se encuentran localizados cerca del río Mojones, el cual es actualmente un curso con escurrimiento efímero e inestable, en un ambiente de vegetación arbustiva (tolas) y donde los suelos son de escaso desarrollo. El río tiene varias terrazas fluviales, dos de las cuales se componen de paleoturberas de edad Holocena Tardía (Figura 2). Esta evidencia geológica nos permite generar modelos de los escenarios ambientales, que sirven para responder interrogantes acerca de si el río fue en algún momento permanente, cómo fueron sus cambios paleohidrológicos y si la ocupación de los sitios estuvo influenciada por estos cambios en asociación a la disponibilidad de agua y forraje. En resumen, los escenarios ambientales permitirán comprender mejor la relación que existió entre la ocupación humana de los sitios arqueológicos y el sistema hídrico. Asimismo, la respuesta a estos interrogantes permite conocer la dinámica del sistema hidrológico a través del tiempo y cómo llevar adelante medidas de mitigación para luchar contra la desertificación (Navone 1998).

Por lo tanto, el objetivo del presente trabajo es describir y evaluar la evolución paleohidrológica en la cuenca inferior del río Mojones-Nacimientos durante el Holoceno Tardío en dirección a generar las primeras hipótesis y modelos paleoambientales conceptuales a escala local, que vinculen la evolución del paisaje fluvial y brinden un contexto ambiental para los patrones organizativos de las sociedades que ocuparon este sector de Antofagasta de la Sierra.

\section{Métodos de Trabajo}

El primer paso fue caracterizar el ambiente actual en términos de disponibilidad de agua y forraje en el entorno inmediato $(<200 \mathrm{~m})$, local $(0,57-10 \mathrm{~km})$ y regional $(10-50 \mathrm{~km})$ de los sitios de Corral Grande. Para ello se identificaron las características de la vega, los cauces permanentes y efímeros, a partir de la interpretación de imágenes satelitales de alta resolución (Google TM). También se utilizó la combinación de

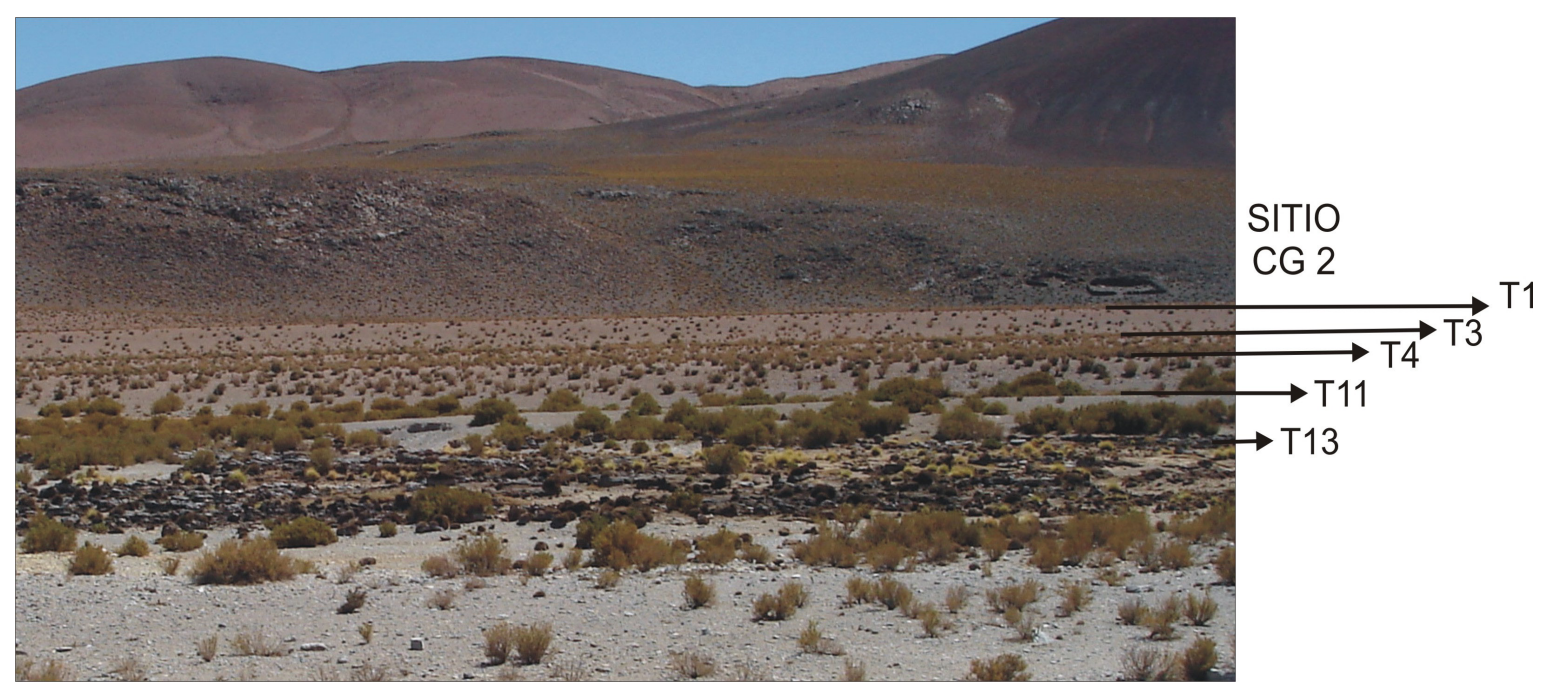

Figura 1. Paisaje en Corral Grande, los sitios arqueológicos se sitúan frente a una vega degradada del río Mojones. Se indican los niveles de terraza fluvial presentes frente al sitio CG1. El nivel T13 presenta suelos orgánicos degradados y secos de edad histórica.

Corral Grande landscape. The archeological sites are located in front of a degraded wetland of the Mojones river. The river terrace levels present in front of the CG1 site are indicated. 
bandas 431 de imágenes ASTER de 15 m de resolución y bandas 534 de imágenes LANDSAT 8 de $30 \mathrm{~m}$ de resolución, con el fin de efectuar el mapeo de las zonas con diferente vegetación y humedad (Figura 1).

El segundo paso consistió en delimitar la cuenca hidrográfica e identificar las geoformas y depósitos sedimentarios que podrían tener edad contemporánea a los sitios arqueológicos, como ser las terrazas fluviales del río Mojones y de Los Nacimientos. Para ello se utilizó el modelo digital del terreno (SRTM) con resolución de $15 \mathrm{~m}$ y la interpretación de imágenes satelitales (resolución de 0,5 m). Esto permitió diferenciar los niveles de terraza fluvial, las cuales se les asignó una numeración correlativa siendo el nivel T1
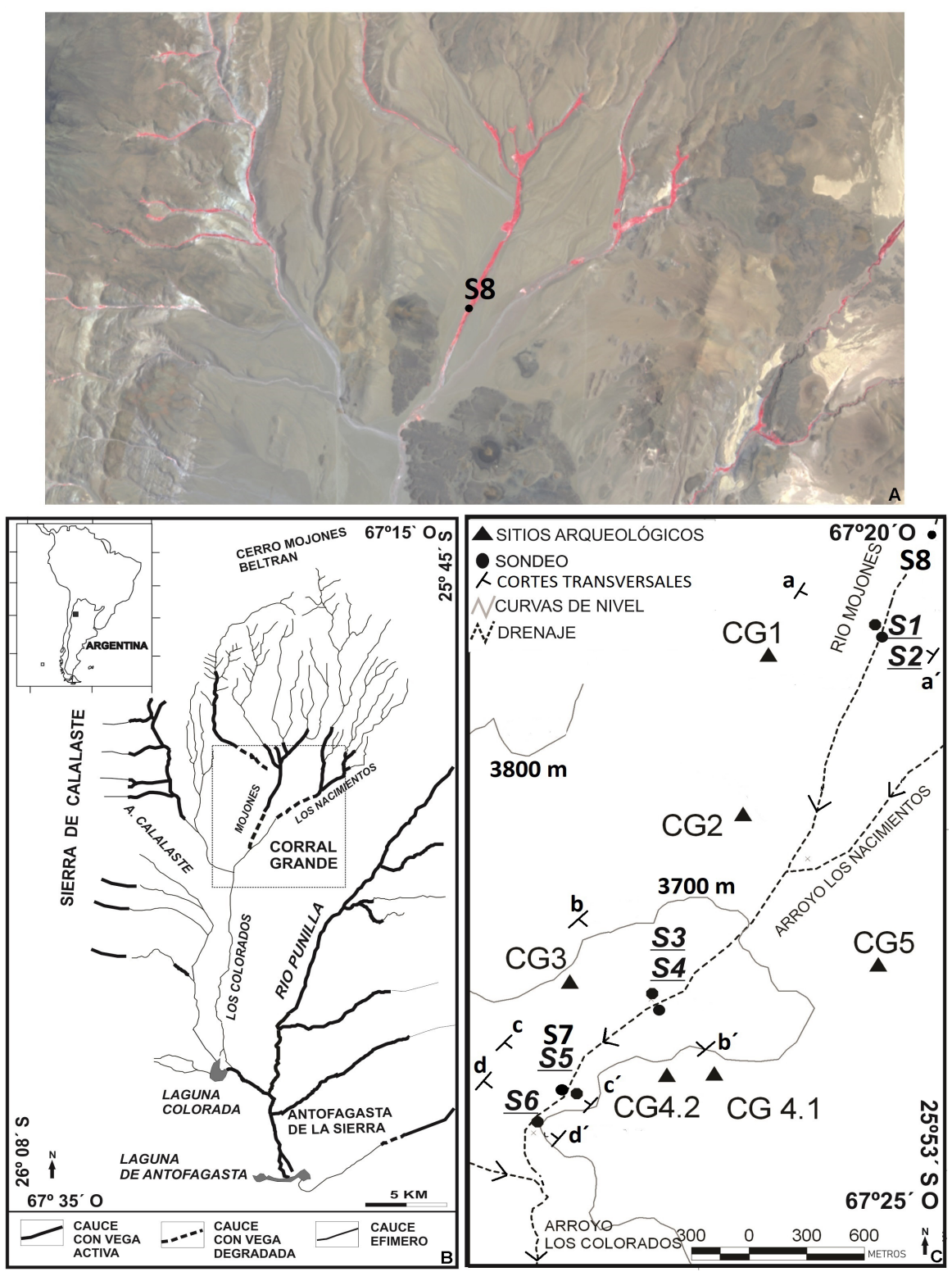

Figura 2. (A) Área de estudio e Imagen satelital LANDSAT8 (16/04/2017) combinación de las bandas 5, 3, y 4. (B) Se indica la ubicación de los sitios arqueológicos, los sectores y (C) de los cortes transversales.

(A) Study area and LANDSAT8 image (16/04/2017, bands 5,3,4). (B) Location of archeological sites and (C) geological cross sections are indicated. 
el más antiguo y T13 el nivel de edad más reciente. La asignación cronológica de los niveles se infirió en base a la altitud. Las terrazas más elevadas fueron asignadas al Pleistoceno debido a que se hallan cubiertas por las efusiones basálticas, muchas de ellas datadas en el trabajo de Risse et al. (2008). Las terrazas de menor altura (T11 a T13) fueron datadas a partir de las edades radiocarbónicas resultantes de este trabajo. Las terrazas que tienen una altitud intermedia intermedia (p.ej. T10, T9, T8 y T7) queda el interrogante en cuanto a su edad Pleistocena u Holocena debido a la falta de dataciones certeras.

Los estudios paleoambientales se efectuaron a partir de análisis estratigráficos utilizando proxies pedológicos, sedimentológicos y diatomeas en base a perfiles expuestos y sondeos (denominados S1 a S8) ubicados en depósitos aluviales y situados frente a los sitios arqueológicos (Figura 1). Las dataciones radiocarbónicas se efectuaron en sedimentos orgánicos (paleosuelos) con el método AMS en el laboratorio de NSF-Arizona (Universidad de Arizona, E.E.U.U.) para verificar que los archivos ambientales tengan una cronología contemporánea con la ocupación humana de los sitios (Tabla 1).

Para los análisis de la granulometría, de las estructuras sedimentarias, del color y el espesor de las capas y las características paleopedológicas, se utilizó el código de litofacies de Miall (1990) y Leopold et al. (1992) modificado (Tabla 2). La interpretación paleoambiental se efectuó en base al agrupamiento de las litofacies que se indican en la Tabla 3. De esta forma cada facie se asocia a un régimen hidrológico, a una profundidad freática, una capacidad de transporte del fluido y una biomasa particular. La estratigrafía se basó en las discontinuidades erosivas reconocidas en todos los sondeos y perfiles (North American Commission on Stratigraphic Nomenclature [NACSN] 2005). Las unidades establecidas son identificadas con letras mayúsculas $(\mathrm{A}, \mathrm{B}, \mathrm{C})$, mientras que las subunidades estratigráficas con letras y números (A1, B1, C1). Estas últimas se reconocen a partir del cambio en la asociación de facies sedimentarias. La correlación entre los distintos perfiles sedimentarios se efectuó a partir de las dataciones radiocarbónicas efectuadas, como también a partir de la información pedológica (niveles de paleosuelos), geomorfológica (niveles o superficies de terrazas) y de las superficies erosivas. Para ello se elaboraron cuatro cortes transversales al río cuya ubicación se indica en la Figura 1. En los mismos se indica el nivel de terraza, las unidades sedimentarias y la ubicación de los sondeos previamente comentados.

Como primera etapa de aproximación para evaluar los proxies biológicos (diatomológico) se analizaron 10 muestras provenientes del perfil S6, para determinar

Tabla 1. Dataciones radiocarbónicas AMS y calibraciones. Radiocarbon AMS dating and calibrations.

\begin{tabular}{llllccc}
\hline $\begin{array}{c}\text { Código de } \\
\text { Laboratorio }\end{array}$ & \multicolumn{1}{c}{ Sondeo/Sitio } & \multicolumn{1}{c}{$\begin{array}{c}\text { Profundidad } \\
(\mathrm{m}) / \text { Nivel }\end{array}$} & Material & $\begin{array}{c}\text { Datación } \\
\text { años AP }\end{array}$ & $\begin{array}{c}\delta \text { 13C } \\
\%\end{array}$ & $\begin{array}{c}\text { Rango años calibrados } \\
(2-\sigma) \\
\text { años cal. AP }\end{array}$ \\
\hline AA78538 & S2 & 0,2 & Sedimento orgánico & $241 \pm 38$ & $-28,0$ & $322-23$ \\
AA78535 & S2 & 0,6 & Sedimento orgánico & $305 \pm 43$ & $-26,7$ & $455-152$ \\
AA78539 & S6 & 0,5 & Sedimento orgánico & $1936 \pm 41$ & $-26,9$ & $1928-1726$ \\
AA103190 & S6 & 0,9 & Sedimento orgánico & $1834 \pm 35$ & $-23,3$ & $1822-1610$ \\
AA103194 & $\begin{array}{l}\text { Corral Grande 1, } \\
\text { Recinto 4, PS1 }\end{array}$ & Nivel 4 & Carbón & $1604 \pm 39$ & $-22,8$ & $1537-1365$ \\
\hline
\end{tabular}

Tabla 2. Facies sedimentarias.

Sedimentological facies.

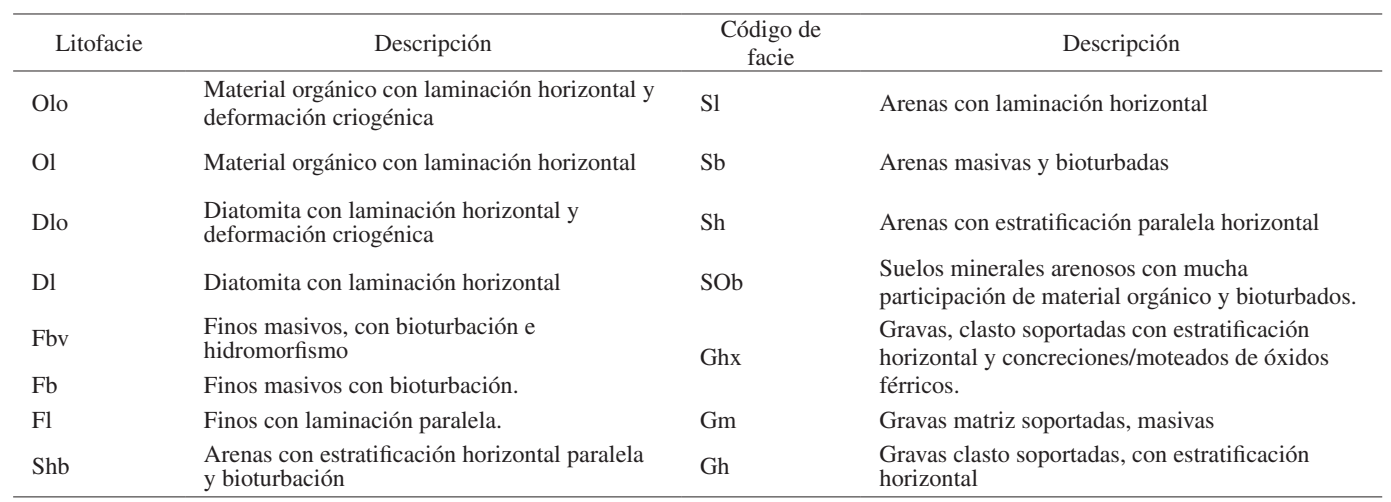


Tabla 3. Asociación de facies sedimentarias.

Association of sedimentological facies.

\begin{tabular}{|c|c|c|c|c|c|c|c|}
\hline Facies & Descripción & Paleoambiente sedimentario & $\mathrm{H}$ & $\mathrm{F}$ & Q & $\mathrm{V}$ & $\mathrm{D}$ \\
\hline Olo, Dlo, Ol, Dl & $\begin{array}{l}\text { Material orgánico y diatomitas laminadas en } \\
\text { capas tabulares, geometrías tabulares }\end{array}$ & $\begin{array}{l}\text { Llanuras de inundación } \\
\text { organógenas }\end{array}$ & 4 & 4 & 1 & 5 & 4 \\
\hline $\mathrm{Fbv}, \mathrm{Fb}$ & Finos con bioturbación, geometrías tabulares & $\begin{array}{l}\text { Llanuras de inundación con } \\
\text { suelos minerales }\end{array}$ & 4 & 2 & 2 & 4 & 3 \\
\hline Ghx, Gh, Dl, Db & $\begin{array}{l}\text { Gravas clasto soportadas con estratificación } \\
\text { paralela y lentes de diatomitas laminadas, } \\
\text { geometrías tabulares. }\end{array}$ & $\begin{array}{l}\text { Canales entrelazados con } \\
\text { barras }\end{array}$ & 3 & 1 & 4 & 3 & 2 \\
\hline
\end{tabular}

H: Régimen hidrológico, 1: inactivo, 2: efímero, 3: permanente estacional, 4: permanente, F: Profundidad y estabilidad de la capa freática, 1: profunda, 2: somera inestable, 3: somera y estable, 4: anegamiento. Q: Capacidad de transporte: 1: Muy bajo, 2: bajo, 3: alto, 4: muy alta. V: Biomasa y vegetación, 1: desierto, 2: arbustiva, 3: pastizal, 4: vega mineral, 5: vega orgánica. D: disponibilidad de recursos de agua y forraje, 1: inexistente a muy bajo, 2 : bajo, 3 : medio, 4 : alto.

las primeras tendencias ambientales y los procesos tafonómicos en este sector ambiental. El tratamiento de las muestras siguió el protocolo estándar establecida por Battarbee (1986). Los preparados se fijaron con Naphrax ${ }^{\circledR}$ y fueron examinados con un microscopio binocular NIKON Eclipse-200 a 100x aumentos. Se establecieron escalas de las abundancias relativas de los taxones observados en cinco categorías: Muy Raro (1-3 valvas), Escaso (4-10 valvas), Frecuente (11-15 valvas), Abundante (16-30 valvas) y Muy Abundante (>30 valvas). La identificación taxonómica e inferencia ecológica se basó en literatura estándar y local (Morales y Vis 2007; Rumrich et al. 2000, Seeligmann y Maidana 2003; Van Dam et al. 1994; entre otros).

La estructura 4 del sitio Corral Grande 1 (CG1), donde se han realizado estudios previos (Olivera et al. 2015), fue seleccionada para realizar un sondeo donde se obtuvo una muestra de carbón asociada a un evento de combustión que determinó una temporalidad del uso del sitio y correlación con el modelo paleohidrológico propuesto en este trabajo. Todos los fechados radiocarbónicos considerados en el presente trabajo fueron calibrados con el programa Oxcal v.4.2.3 utilizando la curva ShCal13 con una dispersión de 2 sigma (95,4 \%) (Bronk Ramsey 1995; Hogg et al. 2013) (Tabla 1).

\section{Ambiente Actual}

La estación meteorológica de Antofagasta de la Sierra (3600 msm) indica precipitaciones menores a 130 mm/año (período 1999-2007) que están distribuidas preferentemente en verano (97\%). La temperatura media anual ronda los $10^{\circ} \mathrm{C}$ y la evapotranspiración promedio es de $1300 \mathrm{~mm} / \mathrm{año}$, siendo mínima en julio y máxima en diciembre. El balance hídrico es negativo durante todo el año, sin embargo, por encima de los $4000 \mathrm{msm}$, el valor de la precipitación aumenta y la evapotranspiración tiene menores valores. Esto queda evidenciado por la mayor frecuencia de nevadas que ocurren en las cuencas altas (14 nevadas en los últimos 10 años), respecto a los sectores con menor altitud (menor a $4100 \mathrm{~m}$ ). En consecuencia, hay una recarga efectiva de los sistemas hídricos subterráneos de alta montaña. Las aguas subterráneas finalmente descargan en vertientes permanentes que son el origen del caudal base de las vegas.

Los sitios arqueológicos de Corral Grande se ubican en la cuenca inferior de los ríos Mojones y Nacimientos. Estos ríos, junto al río Calalaste, son afluentes del río Los Colorados (Figura 1). Las nacientes se sitúan a elevada altitud en los cerros volcánicos Beltrán y Mojones (5500 msm). Hay morfologías glaciarias de edad Pleistocena Tardía, como morenas cuyas terminaciones se sitúan entre 4900 a $4550 \mathrm{msm}$. También aparecen lóbulos de solifluxión activos y mantos de derrubios muy extendidos a más de 5000 $\mathrm{msm}$. La cuenca media tiene dos extensos piedemontes de edad Pleistocena y 4 niveles de terrazas fluviales. La cuenca inferior está formada por un cono aluvial que finaliza en el salar de Laguna Colorada (Figura 1). El sistema fluvial tiene $48 \mathrm{~km}$ de largo desde sus cabeceras hasta su desembocadura en la Laguna Colorada. Está dividido en cinco tramos con diferente tipo de régimen hidrológico. Desde la cuenca superior el río comienza con un régimen efímero estival-nival, alimentado por los deshielos de primavera y ocasionales lluvias de verano. Este tramo no tiene humedales y el río tiene un hábito 
recto entrelazado dando idea de la elevada inestabilidad hídrica y un elevado aporte sedimentario. A partir de los $4300 \mathrm{msm}$ (en la cuenca media-superior), el río tiene un régimen permanente alimentado por cinco vertientes, las cuales se ubican en el valle del río y están asociadas a las fallas inversas de edad Cuaternaria que se disponen con rumbo transversal al escurrimiento. Las fallas favorecen que el agua del subálveo del río aflore en superficie. Entre los 3950 a $3766 \mathrm{msm}$ el río tiene una llanura de inundación de $15 \mathrm{~km}$ de largo con suelos orgánicos saturados y el cauce tiene un hábito anastomótico y sinuoso con numerosos cuerpos de agua (Figuras 3 y 4). Desde una perspectiva ecológica este tipo de ambiente corresponde a un humedal, denominado vega puneña o vega altoandina, y ofrece una mayor disponibilidad y oferta de recursos hídricos para el forraje y la caza, que los restantes ecosistemas de la Puna Salada (Figura 3-B). Entre los 3766 y $3736 \mathrm{msm}$ el río tiene un régimen intermitente. En la planicie de inundación hay suelos orgánicos secos y la capa freática está a $2 \mathrm{~m}$ de profundidad. Los suelos orgánicos tienen grietas de contracción y depresiones por subsidencia producto de la consolidación por el descenso permanente de la capa freática. Estos fenómenos estarían indicando una etapa temprana de degradación de la vega. Entre los 3729 y 3686 msm el río tiene un régimen efímero, con agua durante algunas semanas del invierno o durante las lluvias intensas y la capa freática está a más de $2 \mathrm{~m}$. La vegetación dominante es el Tolar, el cual tiene una abundancia del 30\% y la vega está ampliamente degradada. Por ejemplo, hay surcos de erosión hídrica de 1,2 m de profundidad y paleosuelos de vega en pedestales de erosión afectados por deslizamientos (Figura 4-A).
Adyacente a este tramo se hallan la mayoría de los sitios arqueológicos relevados (Figuras 1 y 2).

Entre los 3686 y 3677 msm, el río es de régimen intermitente posiblemente debido a que el sustrato es impermeable (basaltos) y el subálveo aflora. El cauce tiene diseño sinuoso y, en este tramo, no hay desarrollo de vega ya que la vegetación está formada por arbustos tola con una cobertura del 30\% (Figura 4-B). El caudal es muy escaso $\left(<2 \mathrm{~m}^{3} / \mathrm{dí}\right)$.

A los 3677 msm está la confluencia con el río Calalaste, el cual es efímero y posee un cauce con mayor pendiente $(2,8 \%)$ respecto a la pendiente del río Mojones. En este punto el aporte sedimentario del río Calalaste origina un estrechamiento en el cauce del Mojones. A partir de la confluencia y hasta su desembocadura el drenaje es de régimen efímero y la vegetación dominante es el Tolar el cual ocupa un 5\% a $10 \%$ de cobertura.

Según lo comentado, el sistema fluvial actual posee un gradiente de humedad y de biomasa, siendo mayor en el tramo medio de la cuenca e inmediatamente pendiente abajo de las vertientes, que es donde hay más agua. Aguas abajo, el caudal del río se pierde progresivamente por la infiltración y la evapotranspiración hasta desaparecer.

\section{Paleoambiente}

\section{Geomorfología y depósitos sedimentarios}

En el modelo digital de elevación permitió identificar 13 niveles de terrazas fluviales, donde los niveles más jóvenes presentan mejor representación en la cuenca inferior y los niveles más antiguos
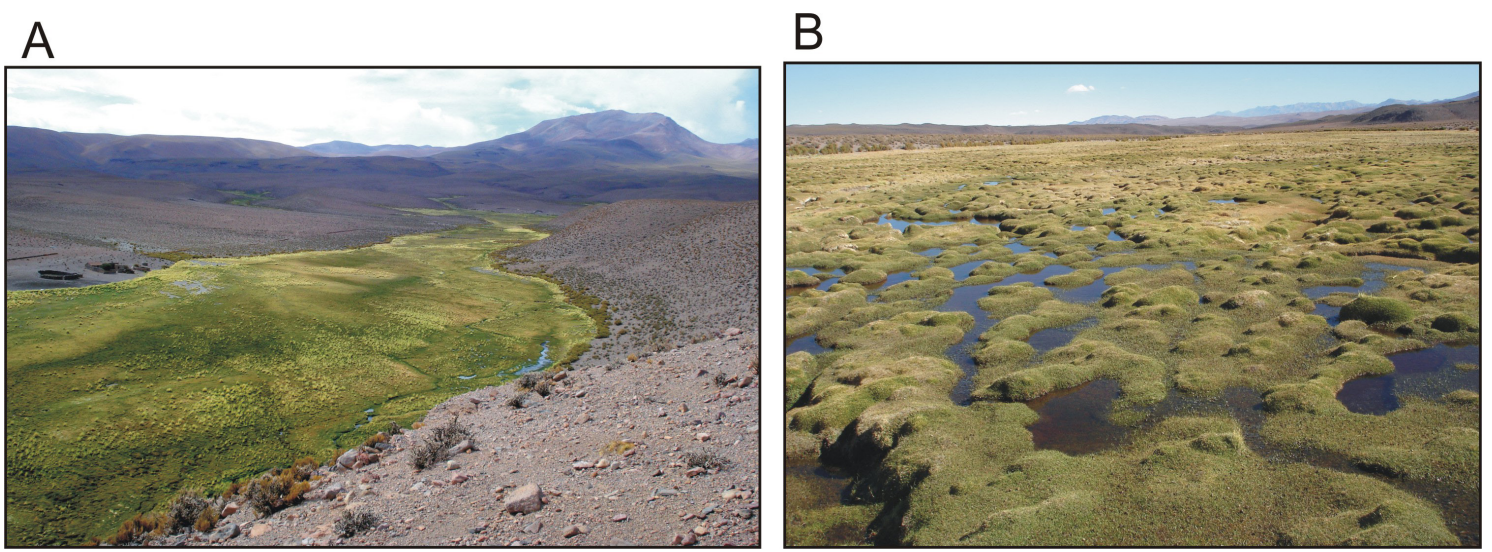

Figura 3: (A) Vega de río Mojones con vista al cerro Mojones. (B) Vega encharcada, con capa freática aflorante y con suelos orgánicos.

(A) Mojones river wetland with a view to the Mojones hill. (B) Flooded wetland with organic soils. 

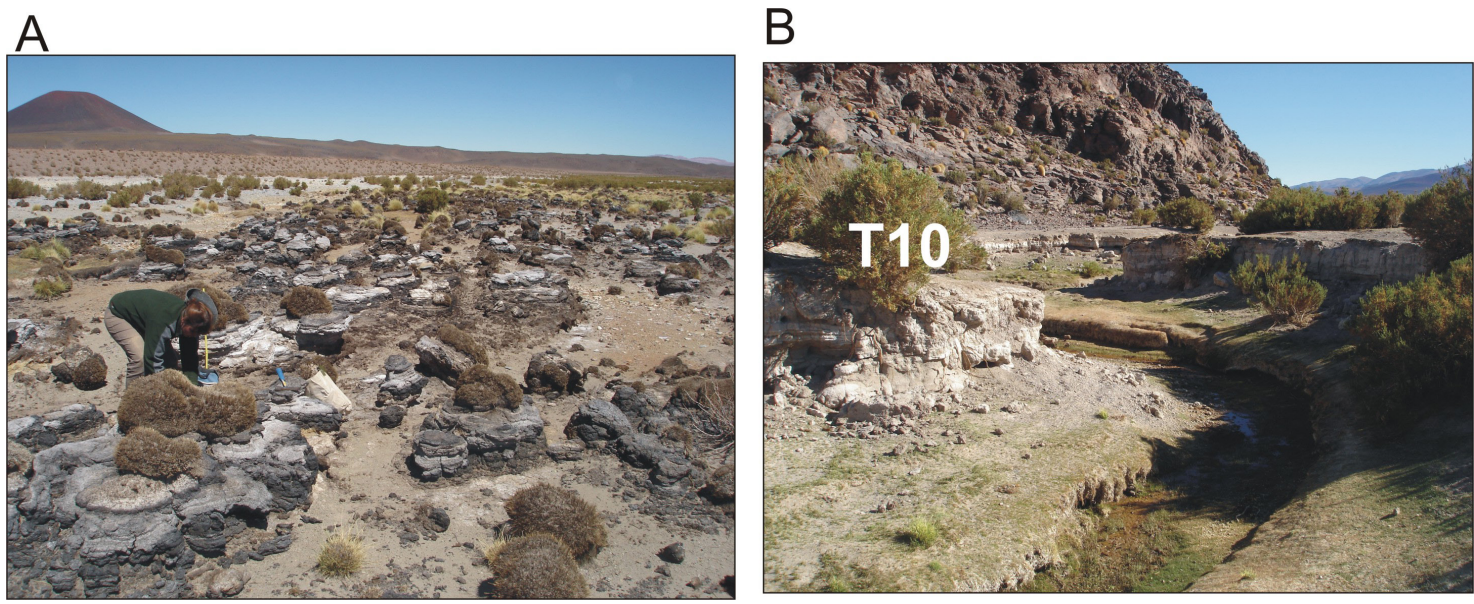

Figura 4. (A) Vega degradada de edad Histórica donde se halla S2. (B) Sector S6 y el nivel de terraza 10.

(A) Degraded wetland of historical age where $S 2$ is located. (B) Sector S6 and fluvial terrace level 10.

están más extendidos en la cuenca superior-media (Tchilinguirian 2008).

Frente a los sitios arqueológicos se reconocen los niveles de terrazas 13, 12, 11, 10, 4, 3 y 1 . El nivel 13 es el de menor desnivel respecto al cauce y el nivel 1 es el de más altitud y el más antiguo (Figuras 2 y 5). Los depósitos de estas terrazas fluviales constituyen archivos ambientales que resultan útiles para interpretar las condiciones paleohidrológicas (Bridgland y Westaway 2008).

Losestudios sedimentológicosy paleopedológicos se centraron en los depósitos de las terrazas fluviales 13, 12 y 11 porque su formación es contemporánea (como se verá más adelante) con la ocupación de los sitios Corral Grande. En estos depósitos sedimentarios se reconocieron tres unidades estratigráficas de interés: A, B y C (Figura 6).

La unidad A tiene dos facies sedimentarias que cambian lateralmente según la ubicación, estando la facie A1 situada río abajo del sitio CG1 (entre cotas 3707 a $3686 \mathrm{~km}$ ) y la facie A2 situada río arriba (entre cotas 3707 a $3950 \mathrm{~km}$ ). En el sondeo S2, la facie A2 forma el cuerpo sedimentario de la terraza 13 , los sedimentos se hallan expuestos y en vías de erosión formando pedestales, terrazas y remanentes de erosión (Figuras 4-A y 7). En S2 tiene $1 \mathrm{~m}$ de espesor y se reconocen tres litofacies. En la base hay paleosuelos minerales de textura arenosa fina y seleccionada de color castaño (litofacie SOb), la parte media está caracterizada por material orgánico oscuro finamente laminado con diatomeas claras (litofacie $\mathrm{Ol}, \mathrm{Dl}$ ) y en la sección superior nuevamente hay paleosuelos minerales de textura arenosa (Figura 7-B). Dos fechados radiocarbónicos realizados en el sondeo S2 a $41-39 \mathrm{~cm}$ y $50 \mathrm{~cm}$ de profundidad presentaron edades de $241 \pm 38$ y $305 \pm 43$ años AP, respectivamente.

Estos sedimentos indican un ambiente fluvial de baja energía y donde los procesos pedogénicos dominaron sobre la erosión y la acumulación de detritos. La paleovega indica que las condiciones fueron anaeróbicas, es decir que fue un sistema fluvial con freáticas aflorantes y estables a lo largo del año. Bajo estas condiciones la materia orgánica se sobreacumuló formando horizontes ricos en restos vegetales. Desde una perspectiva ecológica, la paleovega fue un ambiente que ofreció una elevada disponibilidad de recursos forrajeros, de agua y de caza potencial para la ocupación humana, en contraposición con las actuales condiciones fluviales efímeras halladas frente a los sitios arqueológicos.

La facie A1 es una facie lateral de la A2 y se extiende aguas abajo de la misma. Está representada por los perfiles de los sectores S4 y S7 y se compone de arenas gruesas a muy gruesas, con gravas finas que se hallan bien estructuradas, bioturbadas y con moteados de óxidos de hierro. Tienen una edad estimada de 200 a 300 años AP porque son contemporáneas a la facie A2.

La unidad B se la halla en los sectores S1, S3 y S5. Forma delgados depósitos aluviales gruesos de terrazas de erosión (T12 y T13) o de relleno de paleocauces labrados en la unidad subyacente $\mathrm{C}$ (p.ej. en sondeo S5). Presenta entre 0,4 a 0,6 $\mathrm{m}$ de espesor y se compone de gravas gruesas, matriz sostén, pobremente estratificadas a masivas (litofacie $\mathrm{Gmm}$ ). Fueron depositados por flujos de alta energía, tipos catastróficos y repentinos (Figura 7-A). Este tipo de eventos se asocian a 


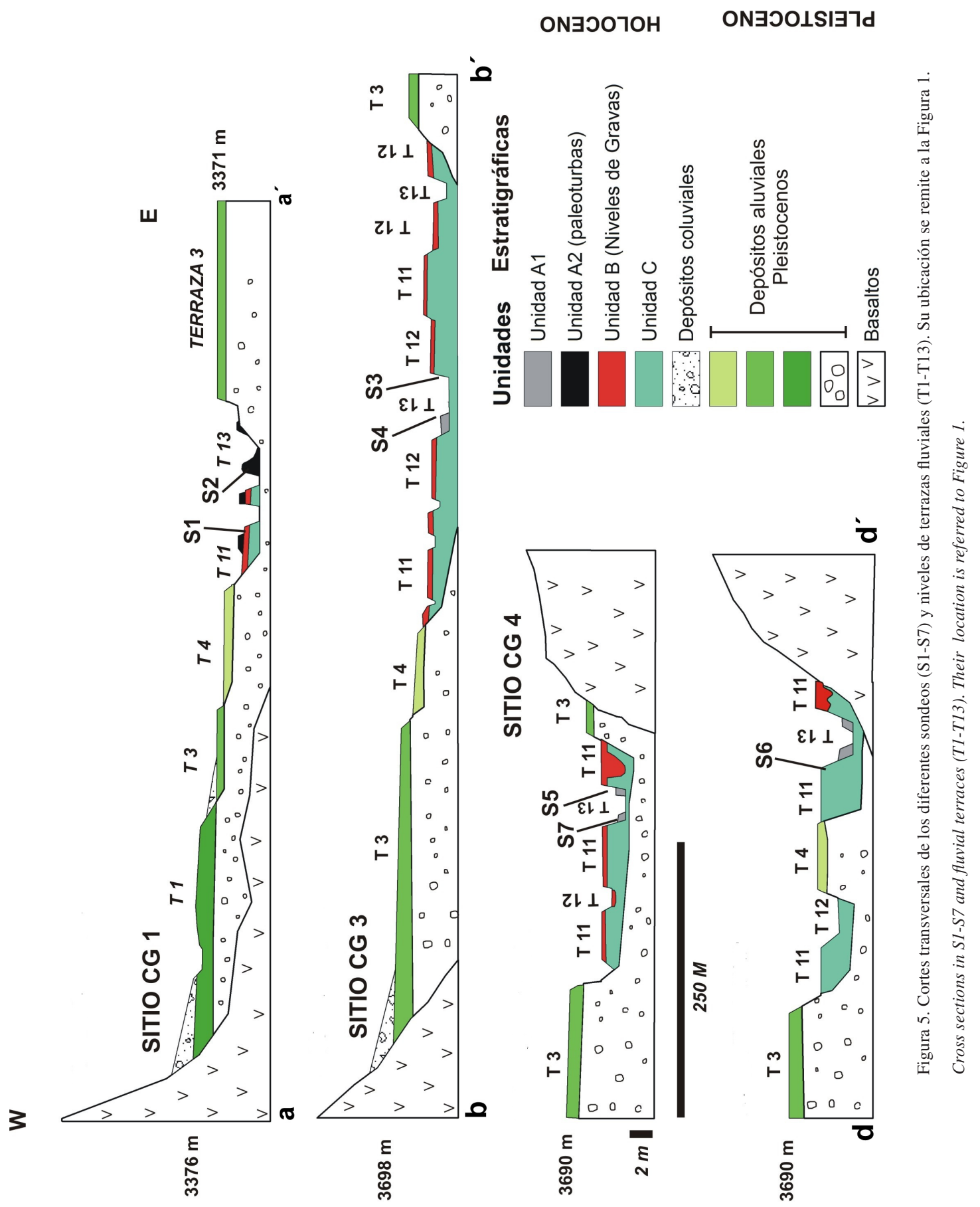



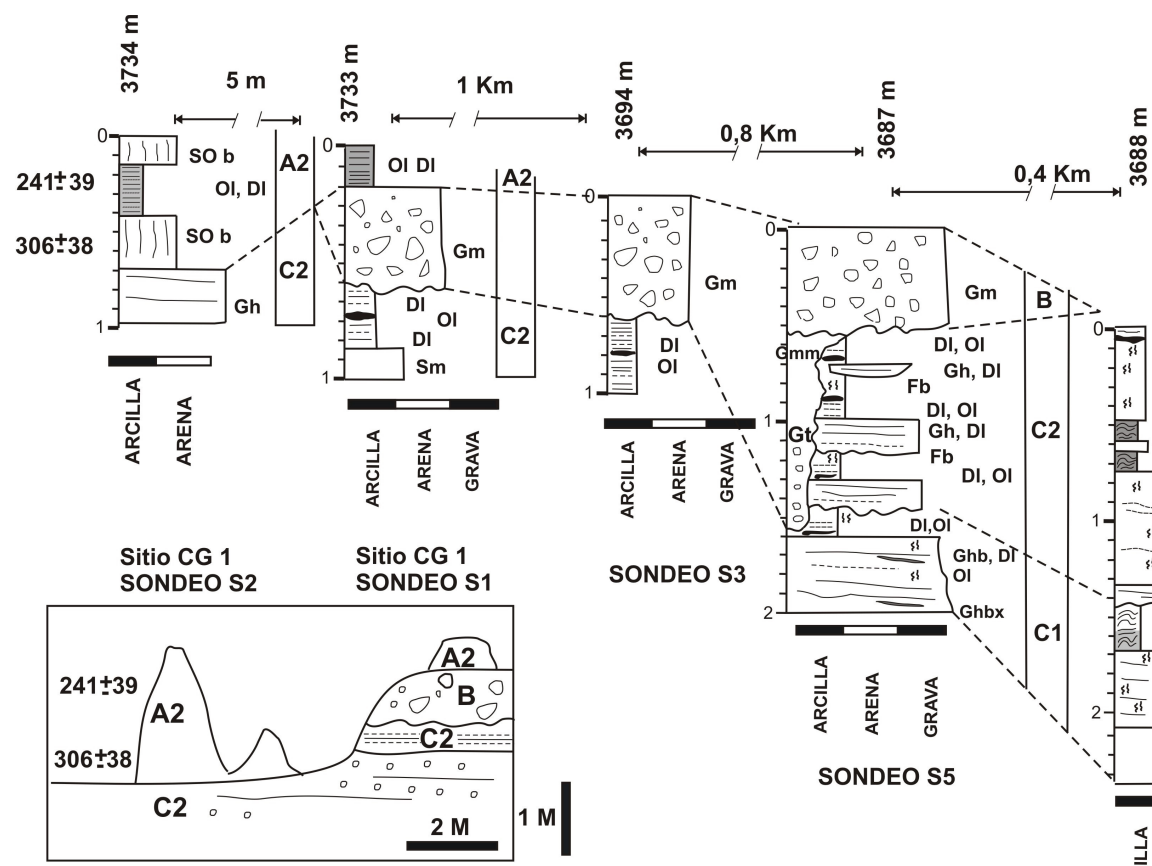

$$
\begin{aligned}
& E \\
& : \\
& 0 \\
& 0 \\
& 0
\end{aligned}
$$
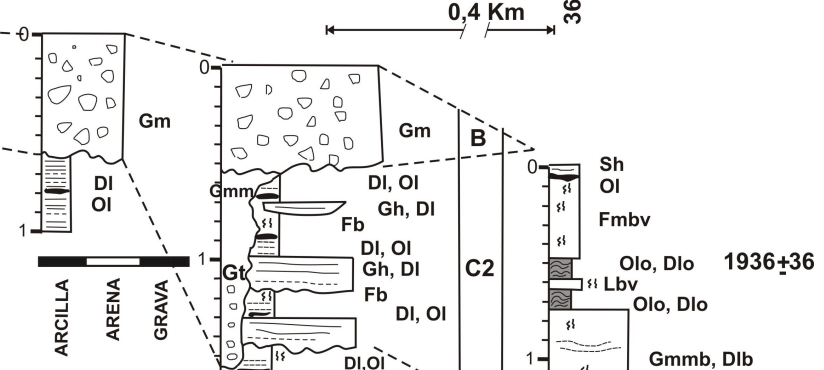

SONDEO S3

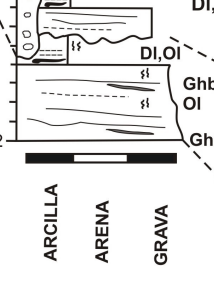

SONDEO S5

Gmmb, DIb

Gh

$1834 \pm 35$

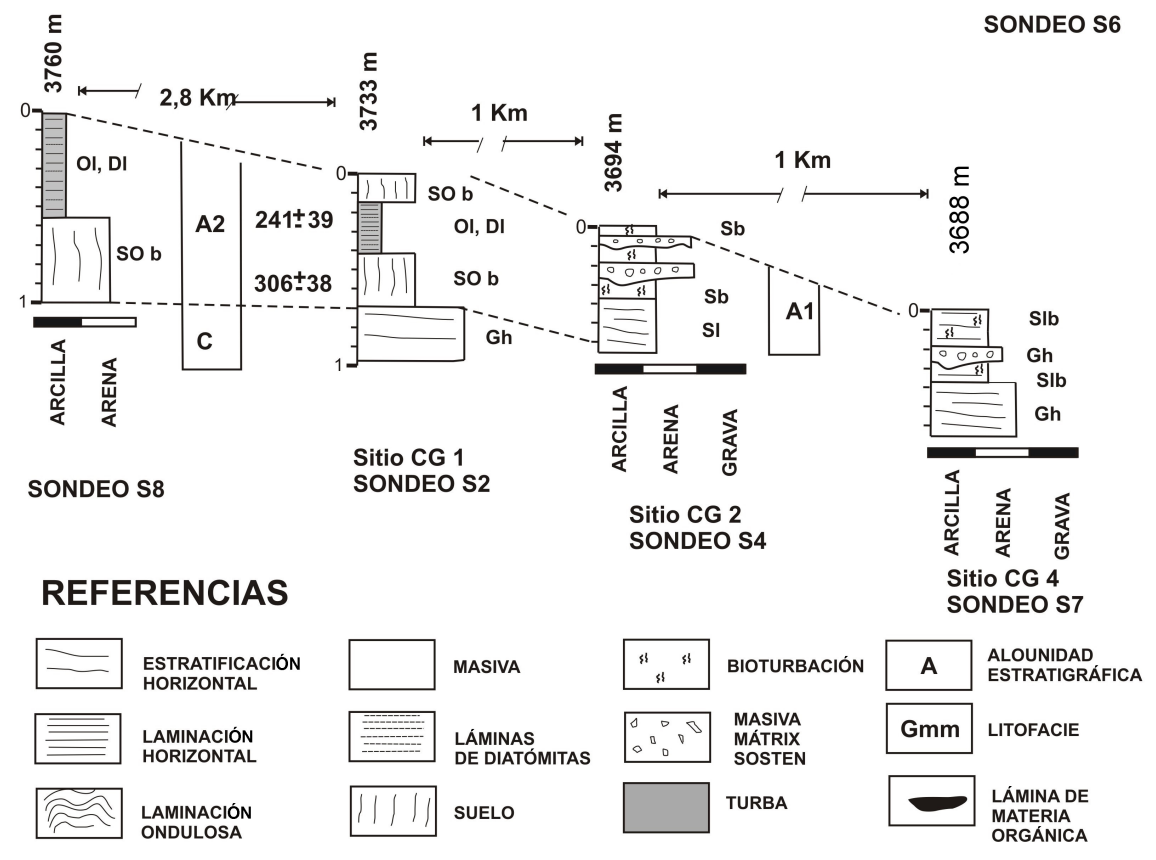

Figura 6. Perfiles estratigráficos en los diferentes sectores. Las letras minúsculas y los subíndices indican las litofacies y las letras mayúsculas las alounidades estratigráficas.

Stratigraphic profiles. The lowercase letters and the subscripts indicate the lithofacies and the capital letters the stratigraphic allounits. 

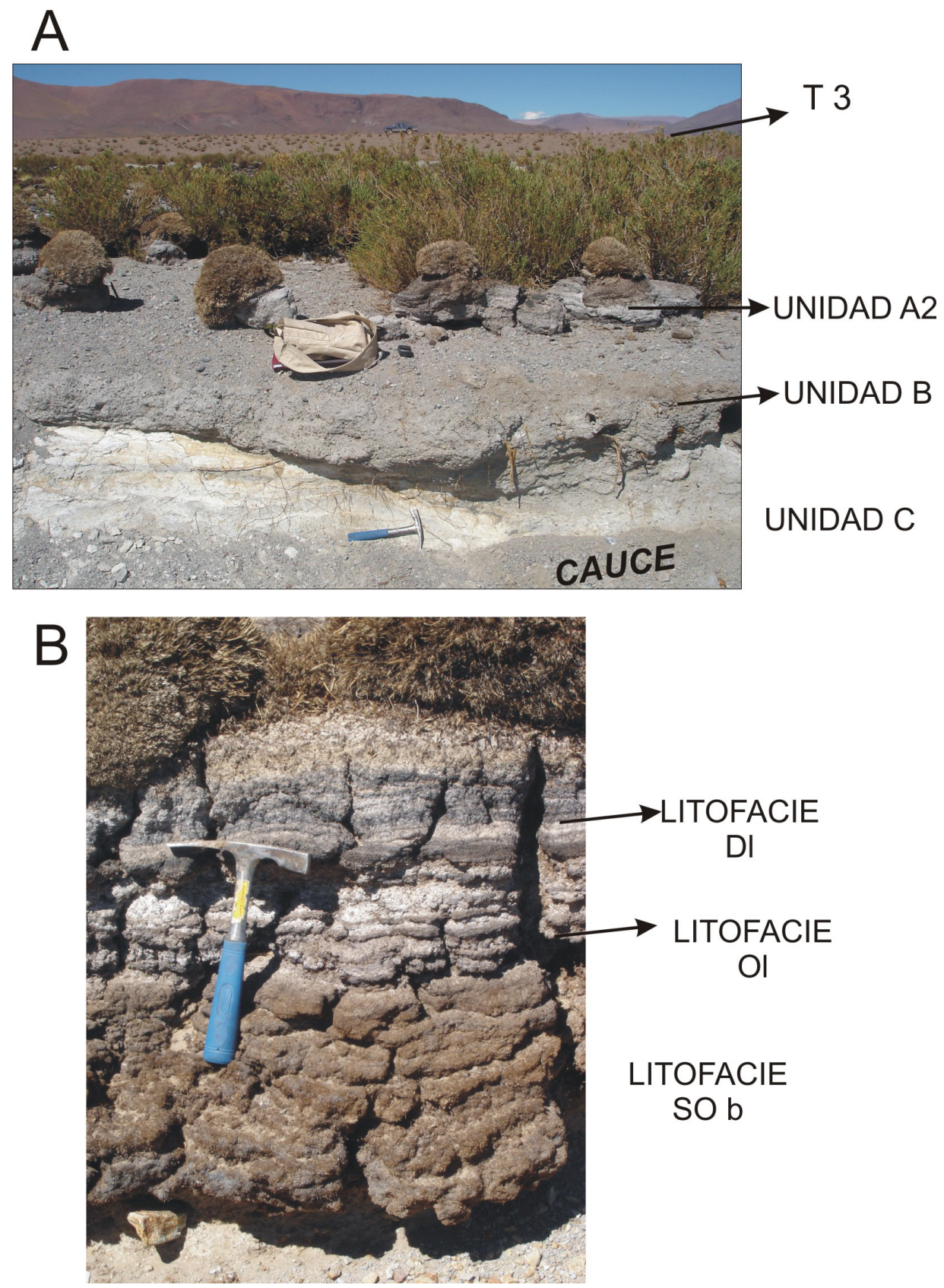

Figura 7. (A) Sector S1 con el nivel de terraza 13. La unidad B es cubierta por la unidad A2 de edad histórica y cubre a las diatomitas de la unidad C. (B) Perfil en el Sector 2.

(A) Sector S1 with fluvial terrace level 13. Unit B is covered by unit A2 of historical age. Unit B covers the diatomites of unit C. (B) Sector 2 sedimentary profile. 
precipitaciones intensas y de muy baja frecuencia. La unidad B, al contrario que la unidad A, se sedimentó en un ambiente fluvial de régimen efímero, con freáticas profundas y sin desarrollo de vega.

En el sector S1, la unidad B está cubierta por las paleoturbas de 200 a 300 años AP de la unidad A2 y está por encima de las diatomitas blancas de la unidad C (Figura 6). En S3 y S5 se halla encima de la unidad C, esta última datada en S6 en $1834 \pm 35$ a $1936 \pm 41$ años AP (Tabla 1). En base a estos datos se estima que la unidad B se depositó a partir de cortos eventos de sedimentación en algún momento entre los 1900 a 300 años AP.

Los sedimentos de la unidad $\mathrm{C}$ se observan en los sectores S1, S3, S5 y S6 en donde constituye el cuerpo sedimentario de la terraza 11 y/o 12. Se compone de dos ciclos de relleno aluvial, donde el basal (C1, Figura 6) se compone varias capas de gravas clastos soportados, con estructuras horizontales y concreciones de óxidos de hierro y con trazas de raíces (litofacie Ghbx). Continúa con capas de diatomita o material orgánico laminado con estructuras ondulosas por la presencia de vegetación en forma de túmulos (litofacie Olo, Dl). Estos sedimentos corresponderían a antiguos paleosuelos orgánicos formados en sectores deprimidos y vegetados de la planicie de inundación.

El segundo ciclo de relleno aluvial (C2, Figura 6) se apoya en discontinuidad erosiva sobre el primero y comienza con la presencia de material grueso matrix soportado y pobremente estratificado o arenas masivas. Ambas tienen colores verdosos, hidromórficos y con bioturbación (litofacies Gmmb, Dlb en S6). Sobre esta última se apoya material orgánico o diatomitas laminadas y con estructuras ondulosas (Litofacie Olo). Se realizaron dos fechados radiocarbónicos en la litofacie orgánica de la unidad C2 y cuyos valores fueron de $1936 \pm 41$ y $1834 \pm 35$ años AP. Por encima de las paleoturbas hay $1 \mathrm{~m}$ de material fino, masivo, bioturbado, de coloraciones verdes con algunas capas de arenas muy gruesas y material orgánico laminado. Estos últimos corresponderían a suelos minerales hidromórficos formados en un ambiente de llanura de inundación. En el tope, hay una lámina de materia orgánica de $2 \mathrm{~cm}$ de espesor, lo que indica que previo a la finalización del ciclo existían condiciones con freáticas someras.

En el sondeo $\mathrm{S} 1$ solamente se reconoce la unidad $\mathrm{C} 2$, compuesta por diatomitas laminadas que son cubiertas en forma erosiva por las gravas gruesas masivas de la unidad B (Figuras 6 y 7-A).

\section{Microfósiles del perfil S6}

En S6 se identificaron en total 67 taxones de diatomeas a nivel especie y variedad, distribuidas en
29 géneros (Figura 8). Sin embargo, hay un alto número de individuos que no han podido ser aún identificados taxonómicamente debido al estado de preservación o tamaño de la valva. Además, algunas especies presentan características morfológicas que indicarían la posible existencia de especies endémicas y nuevas para la ciencia, como es el caso de la nueva especie de Staurosira que aún se encuentra bajo estudio su taxonomía y afinidad ecológica (Grana et al. 2016). Por lo anteriormente apuntado, es esperable que el número de taxones se puede incrementar con estudios futuros y fortalecer así las interpretaciones paleoambientales.

En base a este estudio preliminar, se puede observar que a los 151-123 cm de profundidad los taxones abundantes-muy abundantes son especies cosmopolitan típicas del perifiton y del bentos, como Fragilaria vaucheriae, Ulnaria aff. acus, Nitzschia vitrea, Planothidium lanceolatum y Pseudostaurosira pseudoconstruens, y especies endémicas como Navicula lauca, que suele ser hallada en abundancia en las zonas bentónicas de los humedales de altura de la puna (Maidana et al. 2011). Posiblemente, se trataría de un ambiente litoral desarrollado en momentos anteriores a $1834 \pm 35$ años AP. Posteriormente, salvo $F$. vaucheriae, $N$. lauca y $P$. lanceolatum, el resto de los taxones pasan a tener abundancias raras a muy raras en la parte superior del perfil.

Entre los 97-46 cm (posterior a 1834 \pm 35 años AP, unidad C2), las muestras presentan un alto grado de fragmentación lo que ha dificultado poder llegar a contar el mínimo de 300 valvas. La alta fragmentación con baja disolución de las valvas puede deberse a varios factores, como el producto de un ambiente con alta energía y/o material transportado a través de la red del drenaje fluvial (Beyens y Denys 1982), los efectos postdepositacionales como la compactación de los sedimentos (Flower 1993), y/o el efecto de la herbivoría de los invertebrados (Turner 2002). En relación a la sedimentología la presencia de lentes de gravas fluviales en la unidad C2 indicaría un ambiente con una energía hídrica que es reconocido en este perfil como los situados inmediatamente aguas arriba (sector S5). Esto indicaría un mayor retransporte de materiales, que podría explicar la alta fragmentación de valvas en estas muestras. Sin embargo, para poder evaluar mejor las cuestiones tafonómicas y aclarar las inferencias paleoambientales, es necesario incorporar el estudio de los perfiles proveniente de los tramos superiores de la cuenca. Con respecto a los taxones identificados, que en este sector fueron abundantes a muy abundantes, son F. vaucheriae, P. lanceolatum, N. lauca. y Nitzschia aff. frustulum. Esta última especie bentónica suele ser hallada en diversos ambientes teniendo un amplio rango de tolerancia a la salinidad (Reimer 1954; Lengyel et al. 2015). 


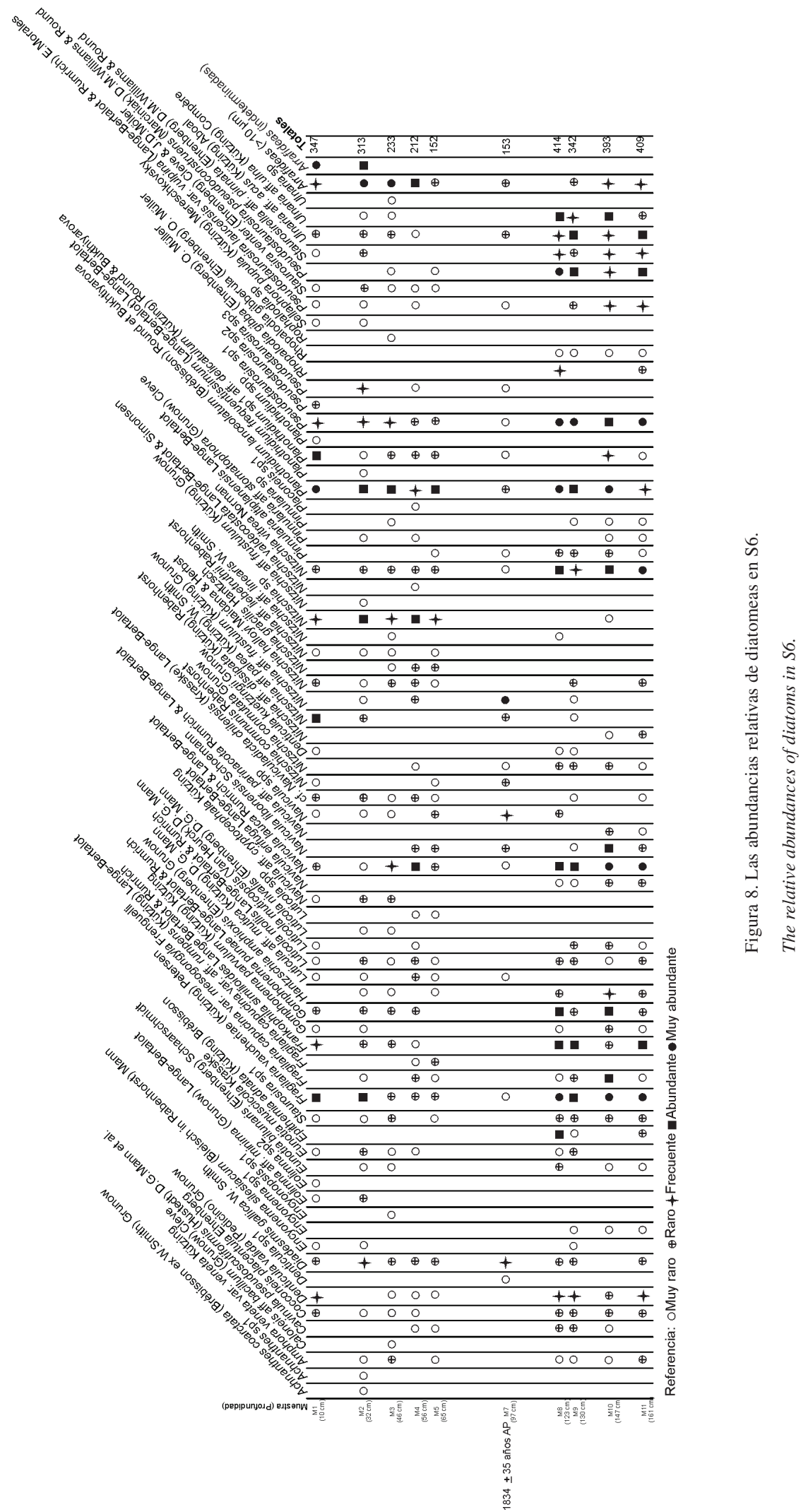




\section{Contexto Arqueológico y Evolución del Sistema Fluvial del Río Mojones}

Los sitios arqueológicos de Corral Grande se hallan ubicados, en su mayoría, entre 60 a $100 \mathrm{~m}$ del río Mojones. Aunque hay sitios algo más alejados como el CG4.2 (Tambo Inka) y CG5 que se sitúan en geoformas estables y de edad pleistocena (Figura 5). Los sitios con estructuras circulares parecen asociarse a momentos ca. 2000 a 1000 años AP, de acuerdo a los materiales cerámicos y líticos que se hallan en superficie y en excavación (Olivera et al. 2008, 2015). En uno de los sondeos del Recinto 4 de CG1, de planta circular, se obtuvo un fechado AMS sobre carbón de 1604 \pm 38 años AP (Tabla 1). Esta fecha coincide con el registro arqueológico asociado en superficie y en excavación, que tiene altas similitudes tecnológicas con el conjunto artefactual del sitio formativo Casa Chaves Montículos (Olivera et al. 2015). Por otra parte, las estructuras de planta rectangular y compuesta presentan material lítico y cerámico en superficie que permite inferir momentos de ocupación posteriores a los 1000 años AP (Olivera et al. 2008). Asimismo, son claras las evidencias arquitectónicas y artefactuales de ocupaciones posthispánicas e históricas, especialmente en CG1. Por lo tanto, puede postularse que este sector del paisaje está caracterizado por sitios multicomponentes y tuvo sumo interés ecológico para las poblaciones de la Puna sur a lo largo de muchos momentos del Holoceno.

Actualmente, el río Mojones es efímero frente a los sitios de Corral Grande y, en consecuencia, no hay agua permanente y forraje cercano disponible durante la mayor parte del año (Figura 9, lapso cronológico: actualidad). Se efectuó una reconstrucción de la paleogeografía fluvial ca. 2000-1800 años AP en base a la identificación de los estratos orgánicos y sedimentos de facies finas de la unidad $C$ que se hallan expuestos en las riberas y en los sectores. También se utilizó el mapeo y la extensión de las geoformas fluviales que albergan los depósitos de esta unidad y que en este caso son la T11 y T12. La reconstrucción paleogeográfica indica que el mosaico hidroecológico fue diferente al actual y el río presentó agua permanente y una extensa vega con buen forraje adyacente a los sitios (Figura 9-lapso 20001800 años AP). En este periodo la capa freática fue aflorante o somera y se desarrollaron suelos orgánicos y/o hidromórficos y vegetación hidrófila o pastizal (unidad C) hasta la desembocadura y confluencia con el arroyo Calalaste. Estas tendencias de mayor humedad son registradas en otros sectores de la región como en el río Miriguaca, río Curuto y en el salar Laguna Colorada (Grana et al. 2016; Tchilinguirian 2008). También es registrado en otras localidades del noroeste argentino, por ejemplo, en el borde oriental de la puna norte los análisis sedimentológicos y polínicos de perfiles de Yavi (Jujuy, Argentino) registran un incremento de la humedad regional y local (Lupo et al. 2015). En la puna de Chaschuil los análisis sedimentológico, geoquímico e isotópico muestran las mismas tendencias (ValeroGarcés et al. 2006).

A partir de los ca. 1800 años AP, la paleovega fue erosionada por la acción fluvial, provocando la disminución de la oferta de recursos. Se observa rellenos sedimentarios en forma de canal en S5 que cortan la unidad B, para que este fenómeno ocurra es necesario que la capa freática se profundice, generando así un descenso del nivel de base.

Tantolapaleovega (duranteellapso 2000-1800años AP) como el comienzo de la erosión es contemporáneo con la ocupación del sitio CG1 (datación de 1604 \pm 39 años AP) y el material de superficie analizado indica momentos del formativo temprano y tardío, debido a la presencia de diversos tipos cerámicos de estilos Ciénaga, Saujil y Aguada (Olivera et al. 2015). Hasta el momento, el material de superficie recolectado permite inferir una funcionalidad de contexto doméstico, debido a que los fragmentos de cerámica analizados indican diversas actividades utilitarias y los materiales líticos se asocian con tareas de procesamiento y/o consumo (artefactos de molienda, raederas, raspadores, trinchetes, muescas, puntas burilantes) (Olivera et al. 2015). Será interesante evaluar si las fluctuaciones ambientales y, por ende, los cambios en la disponibilidad y/o abundancia de los recursos, afectaron la dinámica de ocupación originando períodos de abandono de los sitios o derivaron en el desarrollo de estrategias que permitieran palear la degradación de la vega.

Entre 1800 a 300 años AP el río presentó una fase erosiva y formaron las terrazas de erosión 12 y 11. El depósito de las mismas (unidad B) finaliza en eventos catastróficos de inundación (flujo de detritos, litofacie $\mathrm{Gmm}$, sondeos S1, S3, S5 y S6) que cubrieron lo que quedaba de la vega de época Formativa. Estas evidencias parecen indicar cursos de aguas efímeros y/o inestables. Estos eventos erosivos también son registrados en otras cuencas de la región, como ser los ríos Miriguaca y Curuto ( Grana et al. 2016; Tchilinguirian 2008). La aridización del ambiente en la última parte del Holoceno Tardío es un aspecto que se ha hallado en otros archivos ambientales de los Andes Tropicales Argentinos (Morales et al. 2012; Liu et al. 2005; Lupo et al. 2007; Oxman et al. 2013, Ramírez et al. 2001, Tchilinguirian y Olivera 2012; ValeroGarcés et al. 2003).

Las ocupaciones arqueológicas para estos momentos se asocian a evidencia arquitectónica de recintos rectangulares y con muros más elevados coherentes con la evidencia superficial como fragmentos de posible adscripción Belén del periodo tardío (Olivera et al. 2008; 2015). Esta ocupación del 

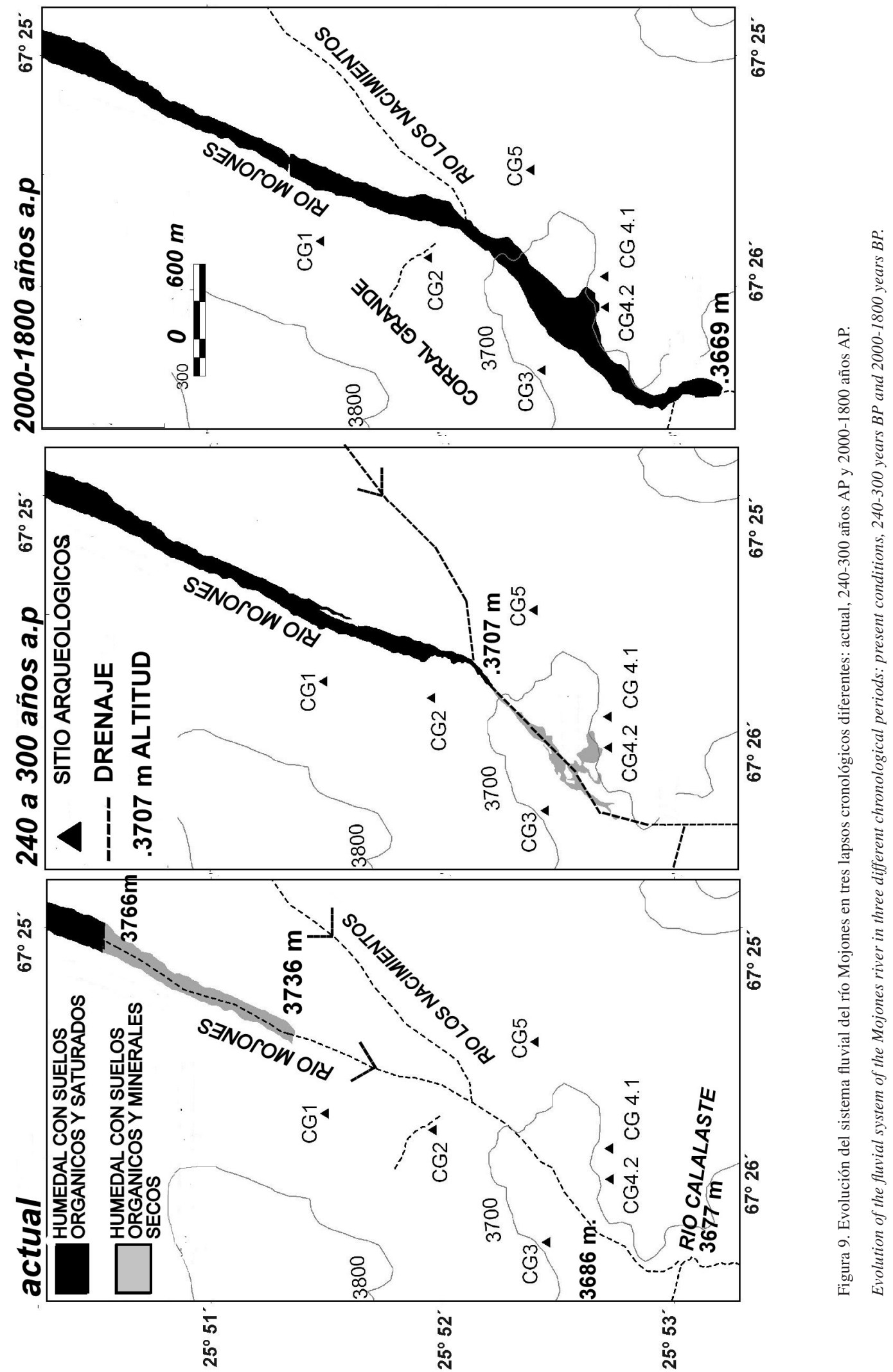
período Tardío en los sitios CG 1, CG4.1 y 4.2, luego de la degradación ambiental antes mencionada, plantea un interrogante interesante: ¿qué sucedió que explique la presencia de una posible ocupación Tardía-Inka en esta cuenca de la región en ambientes con menores recursos que el Formativo?. Por el momento no poseemos una respuesta definitiva a esta pregunta, pero las evidencias arqueológicas son indudables. Quizás una hipótesis pueda asociarse a pulsos de humedad detectados para ca. 500/600 años AP en otros sectores de la macro-cuenca y que pudieron tener su correlato en este sector, contemplando incluso una modificación en la explotación de los recursos, quizás con incremento de la caza y el pastoreo para momentos Tardío-Inka (Tchilinguirian y Olivera 2012). Es oportuno anotar que aguas abajo de la cuenca la actividad agrícola para momentos posteriores a ca. 1000 años AP está bien registrada en los sitios Punta Calalaste (Olivera et al. 2008) y Campo Cortaderas (Olivera et al. 2004), lo que indica el interés que tuvo la cuenca de Calalaste para las poblaciones del Tardío.

En épocas históricas, el río Mojones cambió a un régimen hidrológico permanente, con freáticas someras y estables (Figura 9: lapso 300-240 años AP). Bajo estas condiciones se formó una nueva vega orgánica frente a CG1 y CG2. A diferencia de la paleovega Formativa, la paleovega de edad Histórica tuvo una extensión 5 veces menor. Estas características de un momento de mayor humedad en la Puna argentina se registran también en otros sitios y ha sido asociado al fenómeno climático conocido como "Pequeña edad de hielo" (Lupo et al. 2007; Oxman et al. 2013, Valero-Garcés et al. 2003). La vega Histórica fue contemporánea con la ocupación humana en los sitios CG1, CG4 1 y 2 (Tambo Inkaico).

El asentamiento CG 4.2 se ubica al pie de elevaciones de origen volcánico, a una distancia de unos $400 \mathrm{~m}$ del cauce del río Mojones y de un área de vegas deterioradas asociadas a dicho curso. Se trata de una instalación compuesta por tres grandes recintos perimetrales compuestos (RPC), dos contiguos y uno aislado, más una estructura presumiblemente para encierre de ganado. Los RPC están conformados por muros perimetrales con pequeños recintos adheridos. El material de superficie es escaso y corresponde a materiales líticos de basalto y obsidiana, habiéndose ubicado algunos fragmentos de pala/azada lítica en vulcanita gris. Dentro de los fragmentos de cerámica, donde dominan los no decorados de recipientes utilitarios, se han rescatado algunos cuyas características corresponden al Inka provincial y al Tardío local. Esto último, unido a las características de la arquitectura, nos lleva a la hipótesis que el sitio correspondería a la categoría de Tampu y formaría parte de la extensa red caminera que el Imperio estableció en la región, que guardó gran relación con los sectores de explotación minera. Por otro lado, se destaca la presencia de un antiguo canal que regaba los grandes cuadros, asociados a algunos recintos con cerámica Belén tardía, de CG4.1 para cultivo o forraje, destinándose quizás parte de la reserva hídrica en momentos Históricos al aumento de las áreas de forraje, debido a su poca extensión natural. Estos canales de riego y corrales tardíos están localizados aguas abajo de la paleovega de los 240 años AP, lo que implica que en épocas históricas la vega fue activa y se extendió en estos corrales. Posteriormente, se registra una degradación de la vega lo que podría haber afectado el uso de los corrales, ya que la falta de agua habría afectado las pasturas. Luego de los 240 años AP la vega histórica degradó de manera importante, quizás como consecuencia del descenso de la capa freática. Esta aridización del sistema fluvial habría, posiblemente, provocado el abandono de los mencionados canales de riego de época tardía-histórica y seguramente afectado la dinámica de ocupación del sector.

\section{Conclusión}

Lo analizado en las páginas precedentes permite sostener que el río y la vega en CG tuvieron cambios significativos en cuanto a régimen hídrico, suelos y tipo de vegetación en el transcurso del Holoceno Tardío. Por ende, constituye un sistema ecohidrológico muy sensible a los cambios climáticos y humanos tal como se estudió en otros humedales andinos tropicales (Cuesta et al. 2012).

Un aspecto que se desprende de este trabajo es demostrar por qué las vegas se "expandieron" pendiente abajo y se retrajeron pendiente arriba según el balance hídrico imperante en la cuenca. Cuando la cuenca tuvo un balance hídrico mayor ocurrieron los siguientes procesos: la freática afloró, ocurrió la agradación sedimentaria, se formaron los suelos y se desarrolló la vegetación ribereña-acuática. Todos estos fenómenos se asociaron al crecimiento de la vega pendiente abajo. Caso contrario, cuando hubo balance negativo, la freática se profundizó, la vega se degradó y se retrajo cuenca arriba.

Así, la expansión de la vega pendiente abajo mejoró la disponibilidad y oferta de recursos en las quebradas intermedias permitiendo, quizás, una mayor y más permanente ocupación del espacio durante el Formativo. La relativa contemporaneidad de los fechados radiocarbónicos de las paleoturbas y del sitio CG1 fortalece este último argumento. La paulatina aridización y retracción de la paleovega, entre ca. 1800-300 años AP y luego de ca. 240 años AP habría originado la reducción del área del humedal y, en consecuencia, de la disponibilidad de forraje y del abastecimiento de agua.

Este trabajo intenta mostrar la importante variabilidad y la alta sensibilidad natural de las vegas 
en las cuencas hídricas del desierto de la Puna y en qué medida los cambios climáticos, a diferente escala, del pasado y del futuro pueden impactar en la toma de decisiones de las sociedades andinas. La evolución paleohidrológica del río Mojones parece haber tenido un impacto directo en la toma de decisiones de los grupos humanos y constituye una variable explicativa de la ubicación, el uso, la ocupación y el abandono de los sitios arqueológicos en la localidad de Corral Grande. Esto, sumado al mal uso de los recursos hídricos, como ser un aumento excesivo de la superficie regada y del consumo de agua, constituiría un impacto sinérgico e irrecuperable de áreas agro-productivas en la Puna, proceso que hemos podido documentar en nuestra área de estudio.
Agradecimientos: A la comunidad de Antofagasta de la Sierra por su apoyo en todo momento. A los integrantes del Proyecto Arqueológico Antofagasta de la Sierra por su colaboración en las tareas de campo. Este trabajo fue realizado en el marco de los Proyectos "Paleoambiente, procesos socioculturales e impacto ambiental durante el Holoceno en la Puna Argentina: una aproximación multidisciplinaria (Etapas I y II)" Area: CAMBIO CLIMÁTICO (PIUBACC) R $20620100100007(2011 / 2014)$ y 20620130100003 BA (2014/2017) y "Arqueología Ambiental del Holoceno Tardío en la Puna Argentina". PIP CONICET 112-201101-00567, 2013-2016. Finalmente, a los dos revisores anónimos que ayudaron a mejorar sustancialmente el texto.

\section{Referencias Citadas}

Battarbee, R. 1986. Diatoms analysis. En Handbook of Holocene Paleoecology and Paleohydrology, editado por E. Berlung, pp. 527570. J. Wiley \& Sons, Nueva York.

Beyens, L. y L. Denys 1982. Problems in diatom analysis of deposits: allochthonous valves and fragmentation. Geologie en Mijnbouw 61:159-162.

Bridgland, D. y R. Westaway 2008. Climatically controlled river terrace staircases: A worldwide Quaternary phenomenon. Geomorphology 98: 285-315.

Bronk Ramsey, C. 1995. Radiocarbon calibration and analysis of stratigraphy: the OxCal program. Radiocarbon 37 (2):425-30.

Cuesta, F., M. Bustamante, M.T. Becerra, J. Postigo y M. Peralvo 2012. Panorama Andino sobre cambio climático. Vulnerabilidad y adaptación den los Andes Tropicales. Consorcio para el Desarrollo Sostenible de la Ecorregión Andina - CONDESAN, SGCAN, Lima.

Escola, P., S. López Campeny, A. Martel, A. Romano y S. Hocsman 2013. Re-conociendo un espacio en lugar de un paisaje. Andes 24:397-423.

Flower, R.J. 1993. Diatom preservation: experiments and observations on dissolution and breakage in modern and fossil material. Hydrobiologia 269-270:473-484

Grana, L., N.I. Maidana, E.A Morales y L. Ector 2016. Une nouvelle espèce du genre Staurosira (Bacillariophycées) dans 1'Altiplano, Cordillere des Andes Argentine. Programme et livre des Résumés, 35ème Colloque de L'association des Diatomistes de langue Française, pp. 29. Luxembourg Institute of Science and Technology (LIST), Belvaux.

Grana, L., P. Tchilinguirian, D. Olivera, C. Laprida y N.I. Maidana 2016. Síntesis paleoambiental en Antofagasta de la Sierra: Heterogeneidad ambiental y ocupaciones humanas en los últimos 7200 años ap. Intersecciones de Antropología 17 (especial 4):19-32.

Hogg, A., Q. Hua, P. Blackwell, M. Niu, C. Buck, T. Guilderson y S. Zimmerman 2013. SHCal13 Southern Hemisphere Calibration, 0-50,000 Years cal BP. Radiocarbon 55 (4):1889-1903.
Lengyel, E., A. Kovács, J. Padisák y C. Stenger-Kovács 2015. Photosynthetic characteristics of the benthic diatom species Nitzschia frustulum (Kützing) Grunow isolated from a soda pan along temperature-sulphate-and chloride gradients. Aquatic Ecology 49 (4):401-416.

Leopold, L.B., M.G. Wolman y J.P Miller 1992 Fluvial Processes in Geomorphology. Dover Publishing, Nueva York.

Liu, K., C. Reese y L. Thompson 2005. Ice-core pollen record of climatic changes in the central Andes during the last $400 \mathrm{yr}$. Quaternary Research 64 (2):272-278.

Lupo, L., J. Kulemeyer, A. Sanchéz, E. Pereira y R. Cortés 2015. Los archivos paleoambientales en el Borde Oriental de la Puna y sus respuestas a los cambios naturales y antrópicos durante el Holoceno. Noroeste argentino. Estudios Sociales del NOA 16:39-68.

Lupo, L., M. Morales, H. Yacobaccio, A. Maldonado y M. Grosjean 2007. Cambios ambientales en la Puna jujeña durante los últimos 1200 años: explorando su impacto en la economía pastoril. Resúmenes ampliados del XVI Congreso Nacional de Arqueología Argentina, Tomo III, pp. 151-156. Universidad Nacional de Jujuy, San Salvador de Jujuy.

Maidana, N. I., C. Seeligmann y M. Morales 2011. El género Navicula sensu stricto (Bacillariophyceae) en humedales de altura de Jujuy, Argentina. Boletín de la Sociedad Argentina de Botánica $46(1-2): 13-29$.

Miall A.D. 1990. Principles of Sedimentary Basin Analysis. Second Edition. Sringer press, Verlag.

Morales, M., D. Christie, R. Villalba, J. Argollo, J. Pacajes, J. Silva, C. Alvarez, J. Llancabure y C. Soliz Gamboa 2012. Precipitation changes in the South American Altiplano since 1300 AD reconstructed by tree-rings. Climate of the Past 8:653-666.

Morales, E.A. y M.L.Vis 2007.Epilithic diatoms (Bacillariophyceae) from cloud forest and alpine streams in Bolivia, South America. Proceedings of the Academy of Natural Sciences of Philadelphia 156:123-155. 
North American Commission on Stratigraphic Nomenclature 2005. North American stratigraphic code. American Association of Petroleum Geologists Bulletin 89:1547-1591.

Navone, S.M. 1998. Assesment of thematic mapper imagery for desertification in the Puna region (Argentina). Symposium of resource and environmental monitoring. Tomo 32, pp. 382-391. International Society of Photogramety and Remote Sensing, Budapest.

Olivera, D. 1992. Tecnología y Estrategias de Adaptación en el Formativo (Agro-Alfarero Temprano) de la Puna Meridional Argentina. Un Caso de Estudio: Antofagasta de la Sierra (Pcia. de Catamarca, R.A.). Tesis de Doctorado. Facultad de Ciencias Naturales y Museo, Universidad Nacional de la Plata, Buenos Aires.

Olivera, D., A. Elías, M. Pérez y P. Salminci 2015. Corral Grande 1 y Arroyo Seco: nuevos aportes al Formativo de Antofagasta de la Sierra (Provincia de Catamarca, Puna Meridional Argentina). Comechingonia. Revista de Arqueología 19 (1):37-66.

Olivera, D., A. Elías, P. Salminci, P. Tchilinguirian, L. Grana, J. Grant y P. Miranda 2008. Nuevas evidencias del proceso sociocultural en Antofagasta de la Sierra. Informe de campaña año 2007. Revista La Zaranda de Ideas 4:119-140.

Olivera, D. y S. Vigliani 2000-2002. Proceso cultural, uso del espacio y producción agrícola en la Puna Meridional Argentina. Cuadernos del Cuadernos del Instituto Nacional de Antropología y Pensamiento Latinoamericano 19:459-481.

Olivera, D., S. Vigliani, A. Elías, L. Grana y P. Tchilinguirian 2004. La ocupación Tardío-Inka en la Puna Meridional: El Sitio Campo Cortaderas. Cuadernos del Instituto Nacional de Antropología y Pensamiento Latinoamericano 20:257-277.

Oxman, B., H. Yacobaccio y L. Lupo 2013. Primeros Estudios Paleoambientales en Lapao 2 (Puna Seca) y la señal de la "Pequeña Edad De Hielo” Anuario de Arqueología 2:375-390.

Ramírez, E., B. Francou, P. Ribstein, M. Descloitres, R. Guerin, J. Mendoza, R. Gallaire, B. Pouyaud y E. Jordan 2001. Small glaciers disappearing in the tropical Andes: a case study in Bolivia: Glaciar Chaclataya. Journal of Glaciology 47 (157):187-194.

Reimer, C. 1954. Re-Evaluation of the Diatom Species Nitzschia frustulum (Kutz.) Grunow. Butler University Botanical Studies 11: 178-191.
Risse, A., R. B. Trumbull, B. Coira, S.M. Kay y P. van den Bogaard 2008. 40Ar/39Ar geochronology of mafic volcanism in the backarc region of the southern Puna Plateau, Argentina. Journal of South American Earth Sciences 26 (1):1-15.

Rumrich, U., H. Lange-Bertalot y M. Rumrich 2000. Diatoms of the Andes, from Venezuela to Patagonia/Tierra del Fuego; and two additional contributions, Vol. 09. A. R. G. Gantner Verlag, Königstein.

Seeligmann, C.T. y N. I. Maidana 2003. Diatomeas (Bacillariophyceae) en ambientes de altura de la provincia de Catamarca (Argentina). Boletín de la Sociedad Argentina de Botánica 38 (1-2):39-50.

Tchilinguirian, P. 2008. Paleoambientes Holocenos en la Puna Austral (27-S): implicancias geoarqueológicas. Tesis Doctoral inédita. Facultad de Ciencias Exactas y Naturales, Universidad de Buenos Aires, Buenos Aires.

Tchilinguirian, P. y D. Olivera 2012. Degradación y formación de vegas puneñas (900-150 años AP), Puna Austral (26 S) ¿Respuesta del paisaje al clima o al hombre?. Acta Geológica 24 (1-2):41-61.

Turner, J. 2002. Zooplankton fecal pellets, marine snow and sinking phytoplankton blooms. Aquatic Microbial Ecology 27:57-102.

Valero-Garcés, B, A. Delgado-Huertas, A. Navas, L. Edwards, A. Schwalb y N. Ratto 2003. Patterns of regional hydrological variability in central-southern Altiplano (18-26 S) lakes during the last 500 years. Palaeogeography, Palaeoclimatology, Palaeoecology 194 (1):319-338.

Valero-Garcés, B., N. Ratto, A. Moreno, A. Navas y A. DelgadoHuertas 2006. Los Lagos del Altiplano de Atacama y el Noroeste Argentino como Sensores de Cambios Hidrológicos durante el Holoceno. En Escenarios de Cambio Climático: Registros del Cuaternario en América Latina, editado por M. Caballero y B. Ortega Guerrero, pp. 185-208. Ediciones Unión Mexicana de Estudios del Cuaternario (UMEC) y la Universidad Nacional Autónoma de México (UNAM). México, DF.

Van Dam, H., A. Mertenes y J. Sinkeldam 1994. A coded checklist and ecological indicator values of fresh water diatoms from the Netherlands. Journal of Aquatic Ecology 28:117-133. 
